\title{
Development of antibacterial denture cleaner for brushing containing tea tree and lemongrass essential oils
}

\author{
Yusaku KOSEKI ${ }^{1}$, Rika TANAKA² and Hiroshi MURATA ${ }^{1}$ \\ ${ }^{1}$ Department of Prosthetic Dentistry, Graduate School of Biomedical Sciences, Nagasaki University, 1-7-1 Sakamoto, Nagasaki 852-8588, Japan \\ ${ }^{2}$ Nagasaki University Hospital, 1-7-1 Sakamoto, Nagasaki 852-8501, Japan \\ Corresponding author, Rika TANAKA; E-mail: rikanaka@nagasaki-u.ac.jp
}

\begin{abstract}
We evaluated effectiveness of tea tree oil (TO) and lemongrass oil (LO) for removal of Candida biofilm from denture base resin and their influence on that surface. Biofilm of C. albicans was formed on resins, and immersed in various concentrations of each oil and distilled water (DW). The biofilm removal effect was determined by incubating specimens in RPMI medium containing Alamar blue (AB) and measuring absorbance. Wear test was also conducted, and surface condition of resins was determined using laser scanning microscope and digital microscope. Specimens immersed in the TO and LO solutions tended to have a lower AB value at higher concentrations and longer soaking times. Use of these agents resulted in less surface roughness as compared to DW. Our results suggest that TO and LO were valid to remove biofilm attached to resin with lower levels of abrasion, and these are effective for use in denture cleaner.
\end{abstract}

Keywords: Denture cleaner, C. albicans, Tea tree oil, Lemongrass oil, Wear test

\section{INTRODUCTION}

Debris attached to a denture appliance is generally considered to be denture plaque and typically includes various kinds of microbes, such as Candida species, mainly C. albicans causing denture stomatitis and oral candidiasis, and bacteria that cause oral diseases, and are related to caries and periodontitis development ${ }^{1}$. A recent epidemiological study revealed that denture stomatitis among denture wearers ranges from 15 to over $70 \%^{2}$. Many who use a denture appliance are elderly, whose oral functions and resistance to infection are reduced. Use of a contaminated denture can cause aspiration-related pneumonia or gastrointestinal fungal infection from infected denture plaque, thus seriously threatening the health of the wearer ${ }^{3)}$. Furthermore, deterioration of denture materials can lead to a worsened disease state. Thus, denture care in addition to oral care is necessary to maintain the health of patients.

Proper denture care is attained with various methods, such as mechanical cleaning method such as brushing with a denture brush, chemical washing method such as soaking in commercial denture cleansers, ultra-sonic cleaning method, and combinations of each ${ }^{4,5}$. However, it is sometimes difficult to completely eliminate Candida with these methods ${ }^{6}$, as the acrylic resins used for fabrication of complete dentures are composed of PMMA, a material with a low level of hardness ${ }^{7}$. Elderly individuals may damage the denture surface by inappropriate brushing and it has been shown that small scratches on the denture surface can become a breeding ground for oral pathogens ${ }^{8,9}$. In addition, Tanaka et al. reported damage to a resin surface cause not only by a denture dentifrice containing abrasives but also distilled water $(\mathrm{DW})^{10)}$. Therefore, a novel denture cleaning method that does not cause damage to resin surfaces is needed.
Plant essential oils are used widely for aromatherapy and known to produce relaxation, analgesia, antiinflammation, and antimicrobial effects, as well as others. Among such products, tea tree oil (TO) and lemongrass oil (LO) have been tested against several different bacteria and Candida species, which showed their antibacterial activities $^{11,12)}$. TO, also known as Melaleuca alternifolia oil, has been used as a panacea with safe antiseptic effects for more than 100 years in Australia, and is now incorporated in many pharmaceutical and cosmetic products ${ }^{11}$. In recent years, clinical studies have been performed to investigate its antibacterial effects as an alternative medicine for dermatophytosis and vaginal candidiasis ${ }^{13,14}$. In addition, application of essential oils in the field of dentistry has also received attention, as methods for mouth rinsing with peppermint, TO, and LO with water have been introduced in aromatherapy textbooks. Antimicrobial effects of such oils against oral microorganisms have also been reported, including the caries inducing bacterium Streptococcus mutans, periodontal disease-inducing bacteria Porphyromonas gingivalis and Fusobacterium nucleatum, and oral candidiasis-inducing microorganism C. albicans ${ }^{15}$. $\mathrm{LO}$ is known to have antifungal properties, with the east India type, extracted from Cymbopogon flexuosus, commonly available. LO has also been considered for application as a mouth rinse for preventing oral candidiasis ${ }^{16)}$.

Furthermore, several studies have reported that both TO and LO reduced biofilm formation on denture surface resin, and suggested their use for denture cleaning ${ }^{17-19)}$. However, in clinical situations, many dentures with attached biofilm already developed are washed, though few reports have focused on removal of surface biofilm by use of an essential oil. Therefore, further study is necessary on applying essential oil to cleaning materials for dentures. 
The purpose of this study was to examine whether essential oils are suitable for denture cleaner. The abilities of TO and LO to remove biofilm and influence the denture surface were investigated, as they were considered capable to destroy mature biofilm formed by C. albicans on denture base resin surface. In addition, we speculated that damage to resin surface would be reduced by mechanical cleaning with these essential oils.

\section{MATERIALS AND METHODS}

Essential oils

For the present study, we selected 2 oils that TO and LO (Tree of life, Tokyo, Japan) for our examinations (Table 1). Each essential oil was dissolved in dimethyl sulfoxide (DMSO) and adjusted to a $50 \%(\mathrm{v} / \mathrm{v})$ aqueous solution prior to performing the experiments.

Determination of minimum inhibitory concentration (MIC) and minimal bactericidal concentration (MBC) This study utilized Candida albicans ATCC 18804, which is typically used as a reference strain for analyses of disinfectants and antifungal agents. C. albicans was seeded into Sabouraud agar (Nissui, Tokyo, Japan) at $37^{\circ} \mathrm{C}$ for $24 \mathrm{~h}$, then simple colonies were transferred to tryptic soy broth medium (TSB; Becton, Dickinson and Company, NJ, USA) at $37^{\circ} \mathrm{C}$ with shaking for $24 \mathrm{~h}$. The number of cells was adjusted to approximately $1 \times 10^{6}$ to $1 \times 10^{7}$ cells $/ \mathrm{mL}$ with PBS.

The MIC value to inhibit $C$. albicans was determined using the CLSI M27 liquid dilution $\operatorname{method}^{20)}$, for which $80 \mu \mathrm{L}$ of $50 \%$ (v/v) essential oil was added to a tube with $4 \mathrm{~mL}$ of TSB and mixed by inversion. The concentration of the first standard was $1.0 \%$ per mL. Five tubes were prepared and $2.0 \mathrm{~mL}$ of TSB was added to each tube, then $2.0 \mathrm{~mL}$ was taken from the first tube and added to the second tube, with the same procedure performed with the other tubes. Thus, the final volume in each tube was $2.0 \mathrm{~mL}$ and the essential oil concentrations in the 5 tubes were $1.0,0.5,0.25,0.125,0.0625$, and $0.03125 \%$, respectively. A $100 \mu \mathrm{L}$ aliquot of the pre-culture was added to all of the tubes, then each was incubated in a shaker at $37^{\circ} \mathrm{C}$ for $48 \mathrm{~h}$. The MIC was considered to be the lowest concentration of essential oil to inhibit microorganism growth, which was indicated by clear fluid with no development of turbidity and without visible growth. One hundred milliliters of the first and second lowest concentrations that produced a non-cloudy liquid sample was inoculated into Sabouraud agar at $37^{\circ} \mathrm{C}$ for $24 \mathrm{~h}$. The MBC was considered to be the lowest concentration without colony formation. MIC and MBC values were used in the adhesion and wear assays.

\section{Effects on removal of biofilm-adhesion assays}

A total of 294 specimens were prepared using heatpolymerized acrylic (PMMA) resin for the denture base (Acron, No. 9, GC, Tokyo, Japan), using a conventional method to produce a denture appliance. A wax pattern was formed and buried in dental investment material using a metal dental flask for water-bath polymerization, then the wax was washed out with boiling water. Next, the PMMA resin was packed and polymerized under heating in the metal flask according to the manufacturer's instructions. After polymerization, the resin was trimmed into a disk form $(6 \mathrm{~mm}$ in diameter, thickness $1.5 \mathrm{~mm}$, weight $0.24 \mathrm{~g}$ ) and the surface was polished with a silicone point (Big Silicone Points, HP R2, Shofu, Kyoto, Japan), which resulted it what was assumed to be a clinically acceptable denture-fitting surface. The samples were soaked in water overnight. Prior to use in an experiment, each was sterilized with

Table1 Essential oils used in this study

\begin{tabular}{|c|c|c|}
\hline Product & Code & Component \\
\hline $\begin{array}{l}\text { Tea tree oil } \\
\text { (Melaleuca alternifolia) }\end{array}$ & TO & $\begin{array}{l}\text { Terpene hydrocarbons } \\
\gamma \text {-Terpinen, } \alpha \text {-Terpinen, Terpinolene, p-Cymene, } \alpha \text {-Pinene, } \\
\text { Aromadendrene, Limonene, } \delta \text {-Cadinene, Ledene, Sabinene } \\
\text { Terpene alcohol } \\
\text { Terpinen-4-ol, Terpinolene, } \alpha \text {-Terpineol, Globulol, Viridiflorol } \\
\text { Oxide } \\
\quad \text { 1,8-Cineole }\end{array}$ \\
\hline $\begin{array}{l}\text { Lemongrass oil } \\
\text { (Cymbopogon flexuosus) }\end{array}$ & $\mathrm{LO}$ & $\begin{array}{l}\text { Terpene hydrocarbons } \\
\beta \text {-Karyopherin, Camphene, Limonene } \\
\text { Terpene alcohol } \\
\text { Geraniol, Linalool } \\
\text { Aldehyde } \\
\text { Citral } \\
\text { Ester } \\
\text { Geranyl acetate } \\
\text { Ketone } \\
\text { Methylheptenone }\end{array}$ \\
\hline
\end{tabular}


$0.05 \%$ sodium hypochlorite for $5 \mathrm{~min}$ and immersed in sterilized DW 3 times for 10 min.

C. albicans was inoculated into yeast nitrogen base (YNB) broth (Difco Laboratories, Detroit, MI, USA) supplemented with $50 \mathrm{mM}$ glucose at $37^{\circ} \mathrm{C}$ with shaking for 18 to $20 \mathrm{~h}$. After incubation, the yeast cells were washed twice with PBS and suspended in YNB supplemented with $100 \mathrm{mM}$ glucose. The concentration of suspensions of $C$. albicans was standardized to approximately $1 \times 10^{7}$ cells $/ \mathrm{mL}$. Biofilm formation was determined using the method of Wander et al. ${ }^{21)}$ Briefly, biofilm developed on PMMA surfaces placed into sterilized flat-bottomed 24 well microtiter plates (Iwaki, Tokyo, Japan). An aliquot containing $1.0 \mathrm{~mL}$ of a standard yeast cell suspension was transferred into each well containing a single disc and incubated for $90 \mathrm{~min}$ at $37^{\circ} \mathrm{C}$ in an orbital shaker at $75 \mathrm{rpm}$ (adhesion phase). Next, the medium was aspirated and each sample was washed twice with PBS to remove non-adherent cells from the resin surface. Fresh YNB (2.0 mL) supplemented with $100 \mathrm{mM}$ glucose was then added to each well and incubated for 3 days at $37^{\circ} \mathrm{C}$ in a shaker at $75 \mathrm{rpm}$, during which each sample was washed with PBS and the medium exchanged for $2.0 \mathrm{~mL}$ of freshly every $24 \mathrm{~h}$. After biofilm formation, the samples were separately soaked in different 6 combinations of essential oil and DW, as follows: TO, 1.0 and $0.5 \%$; LO, $1.0,0.5,0.25$, and $0.125 \%$; based on the MIC and MBC values. The soaking times in each solution were 1,3 , and $5 \mathrm{~min}$. Thus, the samples were divided into 21 groups $(n=14)$. After soaking, each sample was placed into a well of a new 24-well plate with $2.0 \mathrm{~mL}$ of RPMI 1,640 medium (Kohjin Bio, Saitama, Japan) supplemented with $10 \%$ of a REDOX indicator (Alamar Blue, Trek Diagnostic Systems, Cleveland, $\mathrm{OH}, \mathrm{USA}$ ) and incubation was performed for $24 \mathrm{~h}$ at $37^{\circ} \mathrm{C}$. Every $6 \mathrm{~h}, 100 \mu \mathrm{L}$ of the supernatant solution was gently transferred to a single well of a 96well plate. Colorimetric changes were determined at 570 and $630 \mathrm{~nm}$ using a Microplate Photometer (Multiskan FC, Thermo Scientific, Waltham, MA, USA). Following the instructions of the manufacturer, the $\mathrm{AB}$ value of each sample was calculated based on absorbance, then the $\mathrm{AB}$ values for the combinations of $\mathrm{DW}$ and $\mathrm{TO}$, and DW and LO were compared.

\section{Effects on denture base resin-wear test}

Twenty PMMA resin (Acron) samples were polymerized according to the manufacturer's instructions, then trimmed into $25 \times 15 \times 2 \mathrm{~mm}^{3}$ pieces. For testing, a mirror surface, with one side coming into contact with a glass plate during polymerization. Before and after the wear test, the surface roughness of 5 random areas of each sample was determined using a laser scanning microscope (Super depth surface profile measurement microscope, VK-8550, Keyence, Osaka, Japan). The mean surface roughness of all samples was $R_{a}=0.17 \pm 0.01$ $\mu \mathrm{m}$, which was near to the value previously obtained with a conventional denture polishing method ${ }^{22)}$. Next, 4 groups of cleaning materials were tested; $1.0 \% \mathrm{TO}$, $1.0 \% \mathrm{LO}, 0.5 \% \mathrm{LO}$ and DW (control). Wear testing was performed with an abrasion testing machine (Rubbing Tester IMC-151B, Imoto Machinery, Kyoto, Japan) ${ }^{10)}$. The sample was brushed with a denture brush (Erac Denture Brush, Lion, Tokyo, Japan) at $200 \mathrm{~g}$ of loading in the direction of the long axis with a $20 \mathrm{~mm}$ trail and up to 10,000 reciprocal strokes, which was considered to simulate denture cleaning for approximately 1 year. Five samples were subjected to each of the cleaning materials. Surface roughness was then measured and surface properties were observed (magnification $\times 1,000$ ) using a digital microscope (VK-5000, Keyence).

\section{Statistical analysis}

$\mathrm{AB}$ values obtained during the measurement period and surface roughness were analyzed using one-way ANOVA and post-hoc Dunnett's analysis. $p<0.05$ was considered to indicate a significant difference. SPSS Statistics software, version 17.0, was used for all statistical analyses (SPSS, Chicago, IL, USA).

\section{RESULTS}

\section{$M I C$ and $M B C$}

In the present study, 2 different essential oil formulations showed antifungal effects towards the ATCC18804 strain, as TO had MIC and MBC values of $0.5 \%$, and LO had an MIC value of $0.0625 \%$ and an MBC value of $0.125 \%$. Those values for LO were less as compared to TO. Therefore, for TO and LO, the concentrations used in the adhesion assay were based on the MIC and $\mathrm{MBC}$.

\section{Adhesion assay}

In Figs. 1 and 2, the effects of soaking in TO and LO on removal of biofilm attached to the resin samples are shown. The AB value after soaking in TO or LO showed a low tendency at a high concentration and long soaking time. On the other hand, soaking in $1.0 \%$ TO for 3 or 5 min resulted in a significantly lower $\mathrm{AB}$ value as compared to the control after $12 \mathrm{~h}(p<0.05)$ (Fig. 1B). There were no significant differences between any of the groups after 6, 18, and $24 \mathrm{~h}$ (Figs. 1A, C, D).

Soaking in 0.5 and $1.0 \%$ LO resulted in lower AB values as compared to the control group after 6 and $12 \mathrm{~h}$ (Figs. 2A, B), while those after soaking for $5 \mathrm{~min}$ group were significantly reduced $(p<0.05)$ (Fig. 2A), with the $1.0 \%$ LO group showing a significantly lower value $(p<0.05)$. In addition, $12 \mathrm{~h}$ of soaking resulted in significantly lower values for the 0.5 and $1.0 \%$ LO groups as compared to the control group after $12 \mathrm{~h} \quad(p<0.05)$ (Fig. 2B). There were also significant differences among soaking in $0.5 \%$ LO for $5 \mathrm{~min}$, in $1.0 \% \mathrm{LO}$ for $3 \mathrm{~min}$, in $1.0 \% \mathrm{LO}$ for $5 \mathrm{~min}$, and the control groups after 6 and 12 h $(p<0.05)$ (Figs. 2C, D).

\section{Wear test}

Surface roughness in all groups showed a tendency to increase at the end of the tests (Fig. 3). Surface roughness for the $0.5 \% \mathrm{LO}, 1.0 \% \mathrm{LO}$, and $\mathrm{DW}$ groups was significantly greater than before the start of the experiment $(p<0.05)$. 
A)

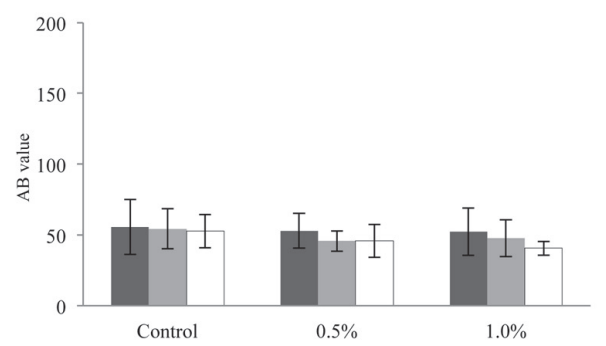

C)

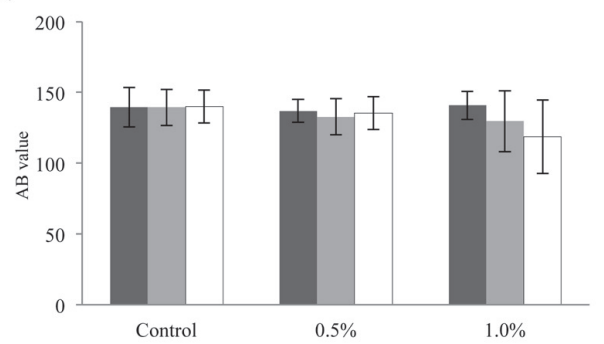

B)

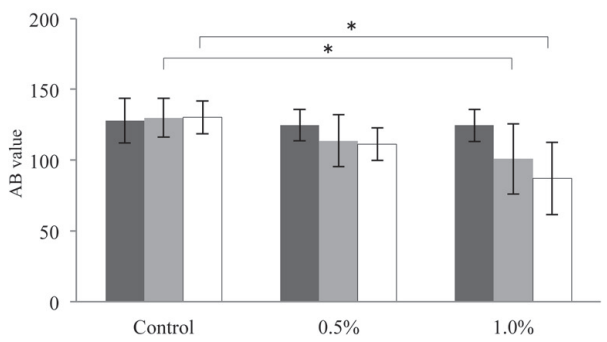

D)

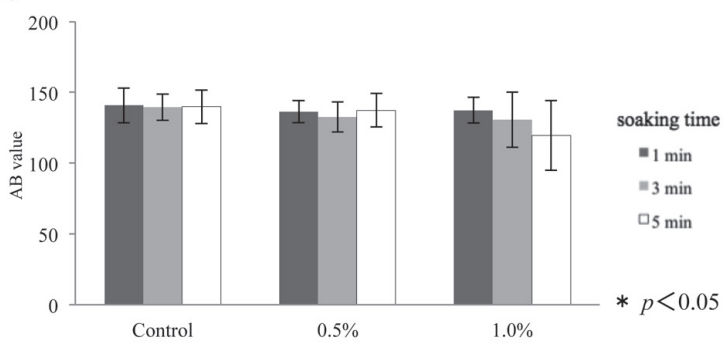

Fig. 1 Effects of soaking in tea tree oil (TO) on removal of biofilm attached to the resins.

After biofilm formation, samples were soaked in TO to remove Candida biofilm. Then, samples were cultured for $24 \mathrm{~h}$ and the activity of surviving bacteria at $6 \mathrm{~h}$ intervals was determined. The $\mathrm{AB}$ value of each sample was calculated based on absorbance and the $\mathrm{AB}$ value of control and TO were compared. Error bars indicate standard deviation, asterisk $\left({ }^{*}\right)$ indicate statistical differences (Dunnett's test, $p<0.05$ ). A) $6 \mathrm{~h}$ later, B) $12 \mathrm{~h}$ later, C) $18 \mathrm{~h}$ later, D) 24 h later.

A)

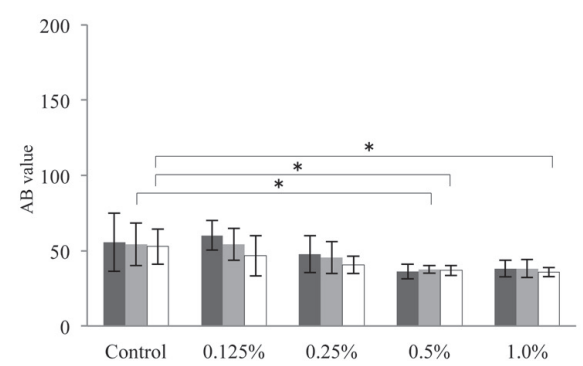

C)

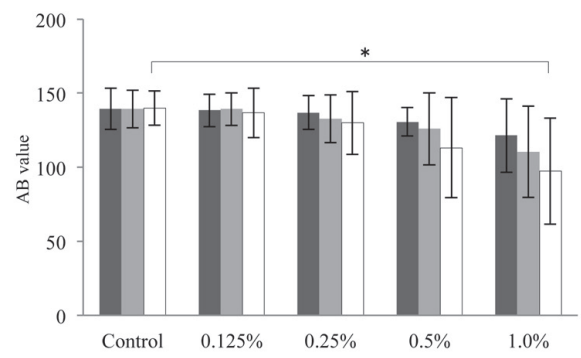

B)

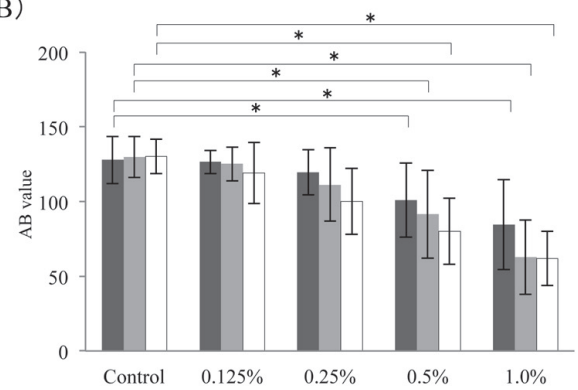

D)

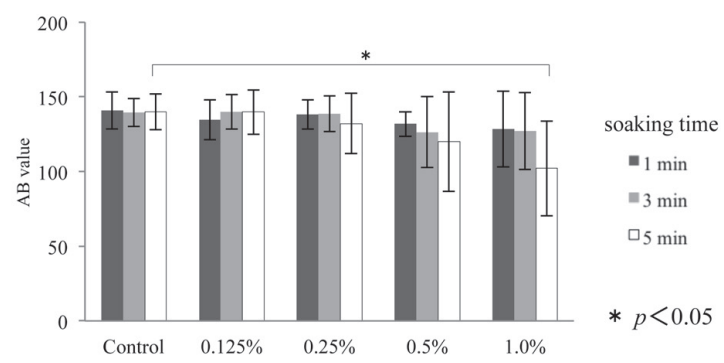

Fig. 2 Effects of soaking in lemongrass oil (LO) on removal of biofilm attached to the resins.

After biofilm formation, samples were soaked in LO to remove Candida biofilm. Then, samples were cultured for $24 \mathrm{~h}$ and the activity of surviving bacteria at $6 \mathrm{~h}$ intervals was determined. The $\mathrm{AB}$ value of each sample was calculated based on absorbance and the $\mathrm{AB}$ value of control and LO were compared. Error bars indicate standard deviation, asterisk ${\left({ }^{*}\right)}^{*}$ indicate statistical differences (Dunnett's test, $p<0.05$ ). A) 6 h later, B) $12 \mathrm{~h}$ later, C) $18 \mathrm{~h}$ later, D) 24 h later. 
That value for DW $(0.23 \mu \mathrm{m})$ was the greatest among all the groups, while surface roughness with $1.0 \% \mathrm{TO}$ was the lowest. There was no significant difference between before and after exposure to $1.0 \%$ TO. Figure 4 presents representative digital microscopic images obtained during the wear tests. With all of the cleaning materials,

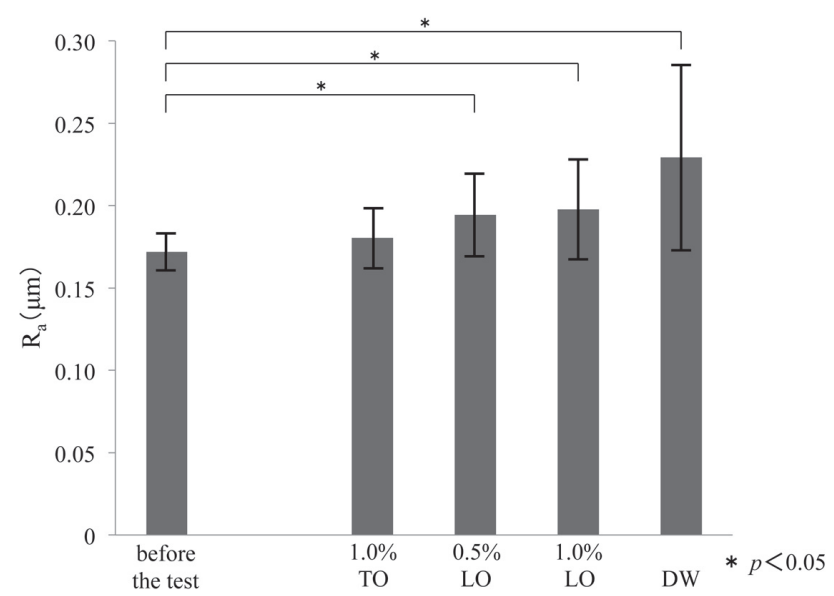

Fig. 3 Results of surface roughness testing.

Error bars indicate standard deviation, asterisk $\left(^{*}\right)$ indicate statistical differences (Dunnett's test, $p<0.05)$. Surface roughness values $\left(\mathrm{R}_{\mathrm{a}}\right)$ of resins for the $0.5 \% \mathrm{LO}, 1.0 \% \mathrm{LO}$, and $\mathrm{DW}$ groups were significantly greater than before the test. grooves formed by brushing were observed, though the $1.0 \% \mathrm{TO}, 0.5 \% \mathrm{LO}$, and $1.0 \% \mathrm{LO}$ groups were similar and showed few wear traces, in contrast to the DW group.

\section{DISCUSSION}

The results of the present study show that TO and LO have antifungal effects against $C$. albicans, which has also been reported in other studies ${ }^{11,14-19)}$. However, LO were more effective than TO based on the MIC and MBC values, and consider that the differences in antifungal effect were related to the individual components of the essential oils. Those with antibacterial activities include the alcohol terpinen-4-ol and the aldehyde citral $^{11,12)}$. We found that the content of terpinen-4-ol in TO was $41.90 \%$, while citral in LO was $67.77 \%$. These components are known to easily combine with proteins, while they promote bacteriolysis by denaturation of cell body proteins, penetration into cytoplasm, and solidification and leakage of cell contents ${ }^{11,14)}$. In other studies, these oils showed antibacterial power at a lower density than glutaral, and are anticipated to function well as substitute disinfectants ${ }^{16,17)}$.

In 2004, the Scientific Committee on Consumer Products in Brussels, Belgium stated that 80-90\% of the contents of $M$. alternifolia oil are monoterpenes ${ }^{23)}$, which is consistent with the TO used in our study [terpinen-4ol $(41.90 \%), \gamma$-terpinene $(20.30 \%), \alpha$-terpinene $(9.30 \%)$, 1.8-cineole $(3.2 \%)$, para-cymene $(2.80 \%)$, $\alpha$-terpineol (2.90\%), $\alpha$-pinene $(2.40 \%)$, terpinolene (3.30\%), limonene
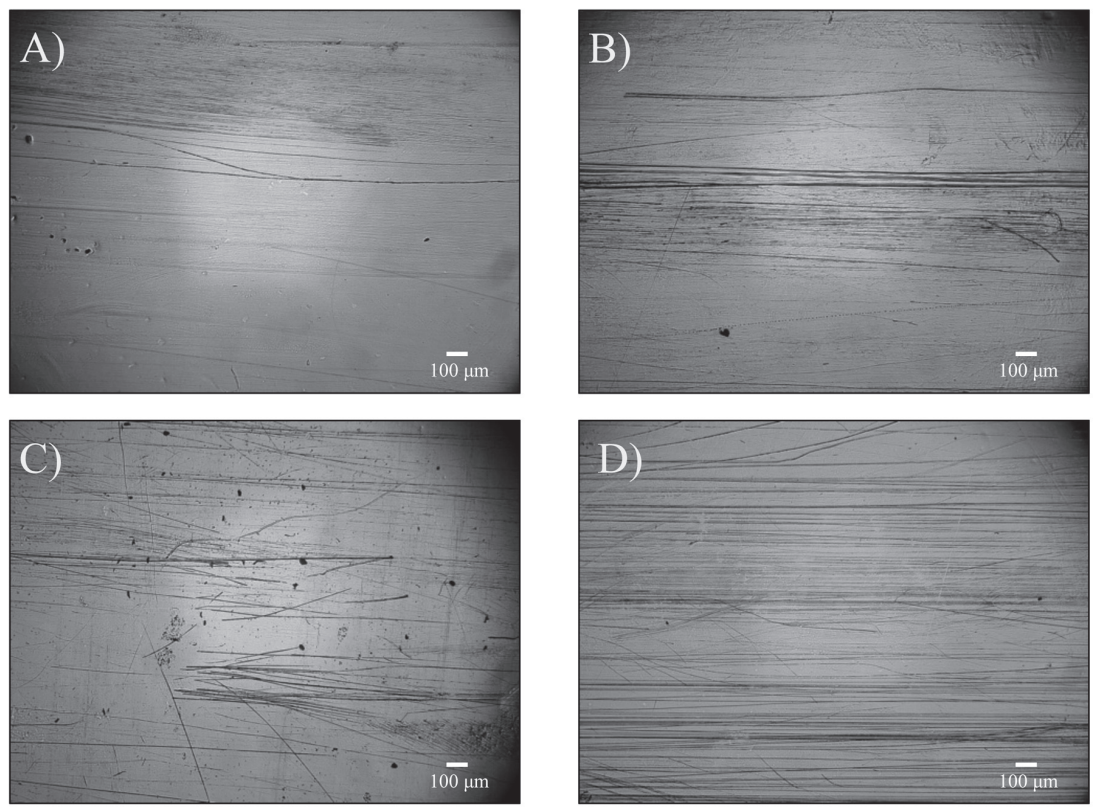

Fig. 4 Representative digital microscopic images of resins obtained during wear test (magnification $\times 1,000$ ).

With all of the cleaning materials, grooves formed of brush were observed. 1.0\% TO, 0.5\% LE, 1.0\% LE had fewer wear traces than the DW group. A) $1.0 \% \mathrm{TO}, \mathrm{B}) 0.5 \% \mathrm{LO}, \mathrm{C}) 1.0 \% \mathrm{LO}, \mathrm{D}) \mathrm{DW}$. 
(1.00\%), sabinene $(0.20 \%) ; 87.30 \%$ of total composition]. Another report also noted that TO showed a MIC of 0.375\% towards C. albicans strain ATCC10231 ${ }^{18)}$. We found that the effect of this oil was caused by its higher density due to the difference in content of terpene related to its growth environment or place of origin.

The results of this laboratory study allow only partial acceptance of the research hypotheses. First, the effect of TO on removal of Candida biofilm was great, as the number of remaining bacteria at $24 \mathrm{~h}$ after immersion in the $1.0 \%$ concentration solution for $5 \mathrm{~min}$ was the lowest, though compared to other TO group. The numbers of remaining bacteria were also lower with the other experimental groups at each measurement point compared to the control group. In addition, the number of remaining bacteria in the $\mathrm{LO}$ groups tended to be reduced when the concentration was higher and immersion time was longer. Particularly, the group with immersion in the $1.0 \%$ LO concentration solutions for 5 min showed significantly lower levels of bacteria $24 \mathrm{~h}$ later. However, we also found that the number of remaining bacteria tended to increase when the incubation time after immersion was extended. As a result, we considered that sterilization was not completely achieved without the active ingredients being taken in deeply to the biofilm with shorter times of immersion of 1 , 3, or 5 min. Therefore, it is expected that biofilm could be removed from resin by $\mathrm{TO}$ and $\mathrm{LO}$ at a higher concentration and longer immersion period.

Studies have been conducted regarding the antibacterial activities of plant essential oils and their influence on biofilm formation on base resin. Dalwai et al. reported that TO was more effective against Candida growth inhibition on heat cured resin as compared to fluconazole ${ }^{17}$. Tobouti et al. noted that Candida have difficulty with surface adhesion following immersion in Melaleuca alternifolia oil ${ }^{18)}$. There are also other reports describing inhibition of biofilm formation by plant essential oils, while ours is the first to show a removal effect.

We formed biofilm on base resin and examined the removal effects of the tested oils after 3 days. Biofilm is formed by $C$. albicans in 4 sequential steps ${ }^{21,24)}$. First, the microorganisms adhere to a surface and the initial colony is organized, which is followed by secretion of extracellular polysaccharide that develops a matrix structure and finally progeny biofilm cells disseminate. In the present experiments, we used $\mathrm{AB}$ as a REDOX indicator for determining removal effects. This agent contains tetrazolium salt and shows color change with a reduction in nicotinamide adenine dinucleotide produced during the process of metabolism by living cells. Since the number of living cells can be determined by quantifying colorimetric change, we utilized this indicator to determine Candida removal ${ }^{25)}$.

In general, biofilm formed in the oral cavity environment includes $C$. albicans as well as other bacteria $^{1,6)}$. A previous study evaluated the effects of chemical cleansers on the pathogenesis of biofilm composed of a mixture of C. albicans and C. glabrata, and it was found that the tested denture cleansers were more effective against $C$. albicans than C. glabrata $^{26)}$. In another study, the predominant oral yeast organisms identified were C. albicans (75\%) and C. glabrata (30\%), which were isolated in higher proportions in patients with the highest grades of inflammation (100 and 80\%, respectively), as well as in combination from $80 \%$ of the examined patients ${ }^{27}$. Additional studies are needed to examine biofilms composed of a mixture of C. albicans and $C$. glabrata in regard to antifungal therapy and pathogenicity.

The second research hypothesis of the present study can be accepted. In the present study, the change of roughness value for $1.0 \% \mathrm{TO}$ was $0.012 \pm 0.013 \mu \mathrm{m}$, for $0.5 \% \mathrm{LO}$ was $0.017 \pm 0.014 \mu \mathrm{m}$, and for $1.0 \% \mathrm{LO}$ was $0.024 \pm 0.027 \mu \mathrm{m}$, which were lower as compared to other studies $^{28)}$, though abrasion traces with use of these agents were observed (Fig. 4). In addition, each was significantly different as compared to DW $(0.049 \pm 0.035$ $\mu \mathrm{m})$ and the other essential oil formulations. Sorgini et al. studied changes in surface roughness of PMMA caused by brushing with a conventional dentifrice and immersion in $0.5 \%$ sodium hypochlorite, and reported that the surface roughness values obtained with sorriso $(1.617 \pm 1.190 \mu \mathrm{m})$ and corega $(1.634 \pm 1.082$ $\mu \mathrm{m})$ were significantly greater as compared to water $(-0.063 \pm 0.013 \mu \mathrm{m})^{28)}$. Fernandes et al. also investigated surface roughness using denture base acrylic resins and found that it was increased after $30 \mathrm{~min}$ of immersion in the examined chemical disinfectants ( $1 \%$ sodium hypochlorite, $2 \%$ peracetic acid) ${ }^{29)}$. Increased surface roughness can facilitate bacterial accumulation, which then promotes development of denture stomatitis, caries, and periodontal disease $\mathrm{e}^{8,9,30)}$. In addition, it was reported that the morphological transformation between fungal blastospores and hyphae in C. albicans biofilm coincides with an increase in surface roughness of denture acrylic resin ${ }^{31,32)}$, a phenomenon attributed to thigmotropism (contact sensing) by C. albicans, in which yeast cells switch to hyphal growth upon contact with a surface $^{33)}$. Invasion of hyphae via a few cracks in resin induces hyphal growth and formation of biofilm ${ }^{34)}$, thus increasing pathogenicity and virulence.

On the other hand, different factors are also involved with the increase of adhesion to a resin surface by bacteria. Other studies have highlighted the role of hydrophobicity in C. albicans biofilm formation on the surface of denture base materials. For example, Klotz et al. observed that a greater number of cells adhered to surfaces with greater hydrophobicity ${ }^{35)}$, though Minagi et al. observed lower adhesion ${ }^{36)}$. Camila et al. evaluated the effects of surface roughness on the hydrophobicity of denture base acrylic resin and $C$. albicans colonization, and suggested that surface roughness ranging from 0.05 to $3.0 \mu \mathrm{m}$ significantly increased hydrophobicity but had no significant effect on $C$. albicans adhesion ${ }^{37)}$. In addition, Gantait et al. examined candidal growth on acrylic resin to elucidate the effects of denture adhesive and denture cleaning methods, and found that denture adhesive increased the adherence of $C$. albicans to a 
resin surface and removal of biofilm by cleanser alone was difficult ${ }^{38)}$.

A limitation of this study is that only a single type of resin was evaluated. Various types of materials with a variety of components, such as artificial tooth resin, metals, and hard and soft denture liners are used clinically. Moreover, there was no simulation of the oral environment or use of denture adhesive. Additional studies are needed to better understand the effects of essential oils with other denture materials.

Several previous investigations regarding denture cleaning methods have found that a combination of mechanical cleaning and chemical washing is desirable for removal of biofilm from denture surfaces ${ }^{4,5,28)}$. Based on results of a 21-day clinical trial, Panzeri et al. suggested that brushing with denture cleaning paste was more effective for removal of biofilm than brushing with tap water ${ }^{39)}$. However, abrasion of the appliance surface by denture cleaning paste and brushing, with subsequent bacterial accumulation in the wear traces are likely to occur ${ }^{2,10,40)}$. Our results demonstrated that TO and LO remove biofilm formed by C. albicans, and their use during brushing also resulted in a lower level of increased surface roughness of denture base resin. Therefore, addition of an essential oil to a denture cleaner for brushing is rational.

\section{CONCLUSION}

Within the limitations of this in vitro study, following are our important results. First, TO and LO each had antifungal effects towards C. albicans. Also, removal of biofilm attached to resin was accomplished by adjusting the concentration and action time of each tested essential oil. In comparison to DW, TO and LO showed a low level of wear when used for brushing denture base resin. Together, our findings suggest the possibility of using TO and LO for removal of Candida as components of denture cleansers for brushing.

\section{ACKNOWLEDGMENTS}

This work was supported by JSPS KAKENHI Grant Numbers 16K15806.

\section{REFERENCES}

1) Nikawa H, Hamada T, Yamamoto T. Denture plaque - past and recent concerns. J Dent 1998; 26: 299-304.

2) Gendreau L, Loewy ZG. Epidemiology and etiology of denture stomatitis. J Prosthodont 2011; 20: 251-260.

3) van der Maarel-Wierink CD, Vanobbergen JN, Bronkhorst EM, Schols JM, de Baat C. Oral health care and aspiration pneumonia in frail older people: a systematic literature review. Gerodontology 2013; 30: 3-9.

4) Paranhos HF, Silva-Lovato CH, de Souza RF, Cruz PC, de Freitas-Pontes KM, Watanabe E, Ito IY. Effect of three methods for cleaning dentures on biofilms formed in vitro on acrylic resin. J Prosthodont 2009; 18: 427-431.

5) Kawasaki K, Kamikawa Y, Sugihara K. In vitro and in vivo removal of oral Candida from the denture base. Gerodontology 2016; 33: 247-252.
6) Lucena-Ferreira SC, Cavalcanti IM, Cury AA. Efficacy of denture cleansers in reducing microbial counts from removable partial dentures: a short-term clinical evaluation. Braz Dent J 2013; 24: 353-356.

7) Pisani MX, Bruhn JP, Paranhos HF, Silva-Lovato CH, de Souza RF, Panzeri H. Evaluation of the abrasiveness of dentifrices for complete dentures. J Prosthodont 2010; 19: 369-373.

8) Radford DR, Sweet SP, Challacombe SJ, Walter JD. Adherence of Candida albicans to denture-base materials with different surface finishes. J Dent 1998; 26: 577-583.

9) Verran J, Maryan CJ. Retention of Candida albicans on acrylic resin and silicone of different surface topography. J Prosthet Dent 1997; 77: 535-539.

10) Tanaka R, Kurogi T, Murata H. Effect of melamine foam cleaning on the surface condition of composite resin artificial teeth. J Prosthodont 2013; 22: 626-632.

11) Carson CF, Hammer KA, Riley TV. Melaleuca alternifolia (Tea Tree) Oil: a review of antimicrobial and other medicinal properties. Clin Microbiol Rev 2006; 19: 50-62.

12) Abe S, Sato $Y$, Inoue $S$, Ishibashi $H$, Maruyama N, Takizawa $\mathrm{T}$, Oshima H, Yamaguchi H. Anti-Candida albicans activity of essential oils including lemongrass (Cymbopogon citratus) oil and its component, citral. J Med Mycol 2003; 44: 285-291.

13) Blackwell AL. Tea tree oil and anaerobic (bacterial) vaginosis. Lancet 1991; 337: 300.

14) Mann CM, Cox SD, Markham J. The outer membrane of Pseudomonas aeruginosa NCTC 6749 contributes to its tolerance to the essential oil of Melaleuca alternifolia (tea tree oil). Lett Appl Microbiol 2000; 30: 294-297.

15) Kakuta E, Ohshima T, Maeda N. Antimicrobial and anti-biofilm forming effects by essential oils against oral microorganisms. Oral Therap Pharmacol 2009; 28: 1-10

16) Satthanakul P, Taweechaisupapong S, Paphangkorakit J, Pesee M, Timabut P, Khunkitti W. Antimicrobial effect of lemongrass oil against oral malodour micro-organisms and the pilot study of safety and efficacy of lemongrass mouthrinse on oral malodour. J Appl Microbiol 2015; 118: 11-17.

17) Dalwai S, Rodrigues SJ, Baliga S, Shenoy VK, Shetty TB, Pai UY, Saldanha S. Comparative evaluation of antifungal action of tea tree oil, chlorhexidine gluconate and fluconazole on heat polymerized acrylic denture base resin -an in vitro study. Gerodontology 2016; 33: 402-409.

18) Tobouti PL, Mussi MC, Rossi DC, Pigatti FM, Taborda CP, de Assis Taveira LA, de Sousa SC. Influence of melaleuca and copaiba oils on Candida albicans adhesion. Gerodontology 2016; 33: 380-385.

19) Madeira PL, Carvalho LT, Paschoal MA, de Sousa EM, Moffa EB, da Silva MA, Tavarez Rde J, Gonçalves LM. In vitro effects of lemongrass extract on Candida albicans biofilms, human cells viability, and denture surface. Front Cell Infect Microbiol 2016; 28: 1-9.

20) National Committee for Clinical Laboratory Standards: Reference method for broth dilution antifungal susceptibility testing of yeasts : Approved standard second edition M27-A2. NCCLS, Wayne, Pennsylvania, 2002

21) da Silva WJ, Seneviratne J, Samaranayake LP, Del Bel Cury AA. Bioactivity and architecture of Candida albicans biofilms developed on poly (methyl methacrylate) resin surface. J Biomed Mater Res B Appl Biomater 2010; 94: 149-156.

22) Kuhar M, Funduk N. Effects of polishing techniques on the surface roughness of acrylic denture base resins. J Prosthet Dent 2005; 93: 76-85.

23) ProductsSCoC. Tea tree Oil. Brussels, 2004.

24) Nikawa H, Nishimura H, Hamada T, Makihira S, Samaranayake LP. Relationship between thigmotropism and Candida biofilm formation in vitro. Mycopathologia 1999; 144: 125-129.

25) Tiballi RN, He X, Zarins LT, Revankar SG, Kauffman CA. 
Use of a colorimetric system for yeast susceptibility testing. J Clin Microbiol 1995; 33: 915-917.

26) de Freitas Fernandes FS, Pereira-Cenci T, da Silva WJ, Filho AP, Straioto FG, Del Bel Cury AA. Efficacy of denture cleansers on Candida spp. biofilm formed on polyamide and polymethyl methacrylate resins. J Prosthet Dent 2011; 105: 51-58.

27) Coco BJ, Bagg J, Cross LJ, Jose A, Cross J, Ramage G. Mixed Candida albicans and Candida glabrata populations associated with the pathogenesis of denture stomatitis. Oral Microbiol Immunol 2008; 23: 377-383.

28) Sorgini DB, da Silva-Lovato CH, Muglia VA, de Souza RF, de Arruda CN, Paranhos Hde F. Adverse effects on PMMA caused by mechanical and combined methods of denture cleansing. Braz Dent J 2015; 26: 292-296.

29) Fernandes FH, Orsi IA, Villabona CA. Effects of the peracetic acid and sodium hypochlorite on the colour stability and surface roughness of the denture base acrylic resins polymerised by microwave and water bath methods. Gerodontology 2013; 30: 18-25.

30) Aykent F, Yondem I, Ozyesil AG, Gunal SK, Avunduk MC, Ozkan S. Effect of different finishing techniques for restorative materials on surface roughness and bacterial adhesion. J Prosthet Dent 2010; 103: 221-227.

31) Mayahara M, Kataoka R, Arimoto T, Tamaki Y, Yamaguchi N, Watanabe Y, Yamasaki Y, Miyazaki T. Effects of surface roughness and dimorphism on the adhesion of Candida albicans to the surface of resins: scanning electron microscope analyses of mode and number of adhesions. J Investig Clin Dent 2014; 5: 307-312.

32) Jackson S, Coulthwaite L, Loewy Z, Scallan A, Verran J. Biofilm development by blastospores and hyphae of Candida albicans on abraded denture acrylic resin surfaces. J Prosthet Dent 2014; 112: 988-993.

33) Nikawa H, Nishimura H, Hamada T, Sadamori $\mathrm{S}$. Quantification of thigmotropism (contact sensing) of Candida albicans and Candida tropicalis. Mycopathologia 1997; 138: 13-19.

34) Mayer FL, Wilson D, Hube B. Candida albicans pathogenicity mechanisms. Virulence 2013; 4: 119-128.

35) Klotz SA, Drutz DJ, Zajic JE. Factorsgoverning adherence of Candida species to plastic surfaces. Infect Immun 1985; 50: 97-101.

36) Minagi S, Miyake $Y$, Inagaki K, TsuruH, Suginaka H. Hydrophobic interaction in Candida albicans and Candida Tropicalis. Infect Immun 1985; 47: 11-14.

37) de Foggi CC, Machado AL, Zamperini CA, Fernandes D, Wady AF, Vergani CE. Effect of surface roughness on the hydrophobicity of a denture-base acrylic resin and Candida albicans colonization. J Investig Clin Dent 2016; 7: 141-148.

38) Gantait S, Bhattacharyya J, Das S, Biswas S, Ghati A, Ghosh S, Goel P. Comparative assessment of the effectiveness of different cleaning methods on the growth of Candida albicans over acrylic surface. Contemp Clin Dent 2016; 7: 336-342.

39) Panzeri H, Lara EH, Paranhos Hde F, Lovato da Silva CH, de Souza RF, de Souza Gugelmin MC, Tirapelli C, Cruz PC, de Andrade IM. In vitro and clinical evaluation of specific dentifrices for complete denture hygiene. Gerodontology 2009; 26: 26-33.

40) Haselden CA, Hobkirk JA, Pearson GJ, Davies EH. A comparison between the wear resistance of three types of denture resin to three different dentifrices. J Oral Rehabil 1998; 25: 335-339. 